\title{
Determination of the absolute accuracy of UK chamber facilities used in measuring methane emissions from livestock
}

Article

Accepted Version

Gardiner, T. D., Coleman, M. D., Innocenti, F., Tompkins, J., Connor, A., Garnsworthy, P. C., Moorby, J. M., Reynolds, C. K., Waterhouse, A. and Wills, D. (2015) Determination of the absolute accuracy of UK chamber facilities used in measuring methane emissions from livestock. Measurement, 66. pp. 272279. ISSN 0263-2241 doi:

https://doi.org/10.1016/j.measurement.2015.02.029 Available at https://centaur.reading.ac.uk/39634/

It is advisable to refer to the publisher's version if you intend to cite from the work. See Guidance on citing.

Published version at: http://www.sciencedirect.com/science/article/pii/S0263224115000871

To link to this article DOI: http://dx.doi.org/10.1016/j.measurement.2015.02.029

Publisher: Elsevier

All outputs in CentAUR are protected by Intellectual Property Rights law, including copyright law. Copyright and IPR is retained by the creators or other copyright holders. Terms and conditions for use of this material are defined in the End User Agreement. 


\section{CentAUR}

Central Archive at the University of Reading

Reading's research outputs online 


\title{
Determination of the Absolute Accuracy of UK Chamber
}

\section{Facilities used in Measuring Methane Emissions from Livestock}

T.D. Gardiner ${ }^{1}$, M.D. Coleman ${ }^{1}$, F. Innocenti ${ }^{1}$, J. Tompkins ${ }^{1}$, A. Connor ${ }^{1}$, P.C. Garnsworthy ${ }^{2}$, J. M. Moorby ${ }^{3}$, C.K. Reynolds ${ }^{4}$, A. Waterhouse ${ }^{5}$, D. Wills ${ }^{6}$

${ }^{1}$ National Physical Laboratory, Hampton Road, Teddington, Middlesex, TW11 0LW, UK

${ }^{2}$ The University of Nottingham, School of Biosciences, Sutton Bonington Campus, Loughborough LE12 5RD, UK.

${ }^{3}$ Institute of Biological, Environmental and Rural Science, Aberystwyth University, Gogerddan, Aberystwyth, SY23 4AD, UK

${ }^{4}$ Centre for Dairy Research, School of Agriculture, Policy, and Development, University of Reading, PO Box 237, Earley Gate, Reading, RG6 6AR, UK

${ }^{5}$ Future Farming Systems, SRUC, West Mains Road, Edinburgh, EH9 3JG, UK

${ }^{6}$ Agri-Food and Biosciences Institute , AFBI Hillsborough, Large park, Hillsborough, Co. Down, BT26 6DR, UK

*Corresponding author. E-mail: tom.gardiner@npl.co.uk, Tel.: +44 (0)208943 7143

\begin{abstract}
Respiration chambers are one of the primary sources of data on methane emissions from livestock. This paper describes the results from a coordinated set of chamber validation experiments which establishes the absolute accuracy of the methane emission rates measured by the chambers, and for the first time provides traceability to international standards, assesses the impact of both sensor and chamber response times on measurement uncertainty and establishes direct comparability between measurements made across different facilities with a wide range of chamber designs. As a result of the validation exercise the estimated
\end{abstract}


absolute uncertainty associated with the overall capability across all facilities reduced from $25.7 \%$ ( $k=2,95 \%$ confidence) before the validation to $2.1 \%$ ( $k=2,95 \%$ confidence) afterwards.

keywords: respiration chambers, methane emissions, livestock emissions, calibration, traceability

\section{Introduction}

Methane is a greenhouse gas (GHG) with a global warming potential 33 times that of carbon dioxide (IPCC, 2013). Agriculture is a significant contributor to global methane emissions as evidenced by the 2011 European Union (EU) inventory detailing that 50\% of all methane emissions were attributable to the agricultural sector (European Environment Agency, 2013). Hence, it is clear that the agriculture sector has an important role to play if international commitments to reduce emissions (e.g. European Climate Change Programme target of 20\% reduction by 2020 compared to 1990 levels) are to be met. Currently in the UK livestock emissions (contributing 85\% of methane emissions from agriculture) are calculated using the Tier 1 approach (IPCC, 2006) under the United Nations Framework Convention on Climate Change (UNFCC). The Tier 1 approach is based on using emission factors (EFs) for different livestock categories and associated manures, i.e. no account is made with respect to farm activity or mitigation effort, e.g. breed, age, diet or seasonality (IPCC, 2006). Consequently, the UK Government's Department for the Environment and Rural Affairs (DEFRA) have commissioned a programme of research to address such issues to facilitate movement to a Tier 2 or 3 approach under UNFCC - the Agricultural Greenhouse Gas Inventory Research Platform (http://www.ghgplatform.org.uk/). A key part of this research is work to underpin national measurement infrastructure to ensure that facilities used for 
measuring livestock emissions are producing comparable data that is traceable to the international system of units and has quantified uncertainties, and it is this work that we report here.

A generally accepted method for determining emissions is the respiration chamber where the animal is placed in the chamber for several days with a controlled throughput of ambient air. Measuring the concentration difference between the outlet and inlet combined with the flow rate gives the total emitted methane flux (Grainger et al., 2007; Yan et al., 2010). Historically calorimetry chambers were used to estimate heat production for measurements of energy metabolism (e.g. Armsby, 1908; Cammel et al., 1981; McClean and Tobin, 1987; Derno et at., 2009), which required precise and accurate measurements of oxygen consumption and carbon dioxide and methane production by animals housed in the chamber. However, due to the reasons outlined above the focus has now shifted towards using chambers to determine the impact of animal husbandry practises on methane emissions, often with simpler designs (e.g. Murray et al, 1999, Klein and Wright, 2006; Pinares and Waghorn, 2012).

There have also been several reports comparing chambers to other measurement methods. For example a number of groups have compared the sulphur hexafluoride $\left(\mathrm{SF}_{6}\right)$ technique (Johnson et al., 1994), which involves placing a permeation tube in the rumen to release $\mathrm{SF}_{6}$ tracer gas at a known rate, to respirator chamber measurements of lactating dairy cows. McCourt et al. (2008) found the $\mathrm{SF}_{6}$ technique to measure $75 \%$ that of chambers, whilst Grainger et al. (2007) found a relationship of 102\%. Muñoz et al. (2012) initially found a close correlation (similar to Grainger) between $\mathrm{SF}_{6}$ and chambers, although as testing progressed they found the former began to measure significantly higher. In the later study, removal of the tubes from the rumen revealed that the release rates had dropped on average to 
$66 \%$ of the pre-test rate, i.e. it was concluded that the increased measurements towards the end of the testing were the product of the decrease in $\mathrm{SF}_{6}$ release rate.

There have also been reports of comparisons between respiration chambers and a method involving measuring eructation during milking via sampling air directly from automatic milking machine feed bins (Garnsworthy, 2012). However, rather than being a direct comparison the purpose of their work was to firstly establish if a correlation existed between eructation frequency and associated methane concentration with daily methane emissions. Having found supporting evidence the authors were able to derive an expression to relate measurements made during milking to daily emissions.

Whilst work such as that described above is of great value to the community as it shows the relative comparability of different measurement methods it does not address the absolute uncertainty. Often what is measured is the precision of a method and not the combined uncertainty, which includes both the precision and any sources of bias. For example, two identical methane sensors will have the same precision (noise) but if only one is calibrated against a traceable reference material then they could provide very different readings of the same chamber despite possessing the same precision. Hence, to truly understand the accuracy of any method and to establish the comparability between different measurement systems there must be comparison to an internationally accepted reference point. Historically, the accuracy of chamber measurements has been based on calibration of flow meters and analyser performance (McLean and Tobin, 1987) and measurement of emissions obtained during a weighed release of the target gas into the chambers. Mclean and Tobin (1987) give an extensive review of recommended procedures at that time and Cammel et al (1981) summarise results for a number of published respiration chambers. More recently Hellwing et 
al. (2012) report on the calibration of a simple respiration chamber for cattle. However, the work reported here is, to our knowledge, the first to provide traceability to international standards, assess the impact of both sensor and chamber response times on measurement uncertainty, and establish direct comparability between measurements made across different facilities with a wide range of chamber designs.

This paper describes the results from a coordinated set of chamber validation experiments conducted at 6 chamber facilities at 5 leading agricultural research centres around the UK: the Agri-Food and Biosciences Institute, Hillsborough; the Institute of Biological, Environmental and Rural Sciences in Aberystwyth; Scotland's Rural College, Edinburgh; the Division of Animal Sciences in the School of Biosciences, University of Nottingham; and the School of Agriculture, Policy and Development at the University of Reading.

\section{Materials and methods}

All of the test chambers across the six facilities were based on the same basic design principle (Fig. 1), although there were marked differences in terms of size, flow conditions and age across the different facilities. In all cases, ambient air is drawn into the chamber and mixes with the emissions from the test subject before being vented to atmosphere via an extract duct. An anemometer (hot wire or vane based) is positioned in the extract duct to determine the chamber flow rate whilst an interfaced gas line is used to pump a sample of the extract gas through an analyser to determine the methane concentration. Combining the flow rate and concentration measurements allows the emitted flux to be calculated using in-house methodologies. The details of the chamber designs and the differences between them are beyond the scope of this paper and are only discussed if relevant to the reported observations. 
Whilst incumbent facility staff were present in order to operate chambers and explain configuration differences, all experiments were carried out by independent researchers from the National Physical Laboratory.

A calibrated source of methane flux was produced by dynamically mixing ultra-high purity methane (BOC Gases, $\geq 99.9995 \%$ purity) and nitrogen (Air Products BIP grade, $<50$ ppbv methane equivalents of hydrocarbon contamination) using an bespoke blender based on Aera FC-7000 series mass flow controllers (MFCs). The blender system consisted of two pairs of MFCs. Each pair consisted of a MFC delivering methane and the other delivering nitrogen, with one pair set up for chambers usually measuring sheep and the other for chambers usually measuring cattle. The flows from the MFC pairs were set to provide an approximately constant total flow of gas independent of the amount of methane being delivered. Rather than relying on the manufacturers specifications, each MFC was directly calibrated for flow rate of the relevant gas via weight loss using NPL's gravimetric gas standard preparation facilities, which are recognised by the International Committee for Weights and Measures (http://kcdb.bipm.org/, accessed April 2014) as providing gaseous reference materials for calibration of UK laboratories to internationally validated levels of uncertainty (http://kcdb.bipm.org/appendixc/qm/GB/qm_gb_4.pdf, accessed April 2014). This enabled mass emissions with an uncertainty of $1.0 \%$ (coverage factor of $k=2,95 \%$ confidence level - written as ' $\mathrm{k}=2$, 95\% confidence' hereafter) to be generated. The pair set up for sheep chambers were typically used to deliver $0.4 \mathrm{mg} / \mathrm{s}(\sim 0.035 \mathrm{l} / \mathrm{min})$ of methane in a total flow of $\sim 1 \mathrm{l} / \mathrm{min}$, while the pair set up for cattle chambers were typically used to deliver $6.0 \mathrm{mg} / \mathrm{s}$ ( 0.5 l/min) of methane in a total flow of $3 \mathrm{l} / \mathrm{min}$. The outputs from the MFCs were combined using $1 / 4$ ” stainless steel tubing and Swagelok fittings. The blender system was leak 
tested with soap solution prior to use and the line was isolated overnight and demonstrated to maintain pressure over a 12 hour period with no significant losses.

The source was delivered from the blender via a bespoke sample line and dispersion system into the chambers. The sample line was a single continuous length of $1 / 4$ ” perfluoroalkoxy (PFA) tubing with stainless steel fittings from Swagelok. The dispersion system consisted of a series of $1 / 4$ " Swagelok T-pieces which spread the emission over a volume of $\sim 4300 \mathrm{~cm} 3$ through 18 separate outputs, without putting a restriction on the output flow.

Each facility consisted of several chambers, since in normal operation a group of test animals is passed through all the chambers in order to determine an emission rate of statistical significance. To facilitate evaluation, and help identify the sources of measurement uncertainty, the chambers were considered as having three principal components: the methane sensor; the ducting and flow system extracting gas out of the chamber; and the chamber itself.

All six facilities used infrared gas filter correlation sensors to measure the methane concentrations in the chambers. The sensor responses were tested by applying a series of NPL prepared standards of methane in synthetic air (i.e. $\mathrm{N}_{2}$ and $\mathrm{O}_{2}$ only) designed to span the concentration range typically seen by the particular sensor being tested. The standards were introduced to one of the sensor sample ports using the by-pass flow arrangement shown schematically in Figure 2. This arrangement ensured the sensor was able to take the required sample volume without over-pressuring the input line, together with the ability to rapidly switch between ambient air and calibration gas without disrupting the sample flow. A total of eight calibration standards were prepared specifically for these tests to cover the complete range seen by the different facilities, with methane concentrations from $10 \mathrm{ppmv}$ to 500 
ppmv These standards were prepared in NPL's gravimetric gas standard facilities and traceably certified to an uncertainty of $0.5 \%(k=2,95 \%$ confidence). Each facility's sensor was tested for accuracy, linearity and response time. Carrying out a linear regression between the sensor readings and reference values provided a linear calibration function for the sensor. The response time was defined as the time taken to reach $90 \%$ of the final stable reading $\left(T_{90}\right)$ when the sample was switched from ambient air to calibration gas, in accordance with EN 15267-3. Note that each facility had a data logging system implemented to record the sensor readings, and this was often on a relatively slow timescale compared to individual sensor readings. Therefore manual readings of the sensor were taken every 10 seconds to provide response time data.

The ducting efficiency was tested by directly releasing a known flux of methane inside the ducting close to the interface with the chamber, i.e. the sample delivery pipe (without diffuser) was inserted a few centimetres into the duct. The usual chamber emission flux calculations could then be carried out and compared to the known emission rate from the calibrated methane source, giving a calibration measurement that was not influenced by the chamber itself. If this calculation is carried out after applying the sensor calibration function to the methane concentration readings then the efficiency of the ducting can be determined in isolation. Any deviation from unity could highlight issues with the accuracy of the flow measurement combined with any losses or sampling issues in the duct itself. Time restrictions meant that it was not possible to carry out ducting efficiency measurements for every chamber at every facility, but ducting measurements were made for at least one chamber at each facility to assess any issues with that particular facility’s design and methodology. 
The final stage of each experiment was to release a known flux of methane through the diffuser in the chambers themselves and compare this to the methane flux determined by the facility. A flow diffuser system was used to spread the flow of methane emission, and this diffuser was located at a typical animal head position in each chamber. This measurement provided a direct calibration of the overall chamber emission measurement. However by applying the previously calculated senor calibration function and ducting efficiency to the readings it also allowed the chamber performance to be evaluated in isolation and the function determined for chamber capture efficiency. Since the calibrated methane source could be used to apply a step change to the methane levels inside a chamber, the results from the chamber measurements were also used to determine the response times of the chambers themselves.

\section{Results and discussion}

\section{Calibration of Methane Sensors}

Figure 3 shows the typical response time of one of the methane sensors used in a chamber facility when a methane calibration standard is sampled. In this case the sensor reached $90 \%$ of the stable plateau reading in $37.1 \mathrm{~s}$. Table 1 summarises the results of the methane sensor calibration experiments for all 6 (anonymised) facilities. The test span value gives the range of concentrations over which the sensor was calibrated, while the calibration factor gives the adjustment factor that has to be applied to the sensor reading at span together with the related ( $k=1,67 \%$ confidence) uncertainty. The plateau stability indicates the $1-\sigma$ noise level on the stable plateau reading, and the sensor response times are given by the $\mathrm{T}_{90}$ values. Finally the linearity of the sensor response over the measurement range is given by the $\mathrm{R}^{2}$ value of a linear regression fit to the calibration data. 
All sensors showed good linearity over the measurement range with $\mathrm{R}^{2}$ greater than 0.996 in all cases, and high levels of accuracy with all responses equivalent to the reference value at the 95\% confidence uncertainty level. The plateau stabilities showed a general level of instrument precision of $1 \%$ or better, with reasonably consistent response times varying between $25 \mathrm{~s}$ and $39 \mathrm{~s}$.

These results confirm the general suitability of the methane sensors in the ranges used for each chamber facility. However, there were a number of specific issues that arose from the sensor tests that could have implications for overall facility operations, and these are discussed below:

- All groups performed regular span checks of the sensor using a reference gas to ensure the long-term stability of the measurements, but it is important to ensure that the actual reference gas used provides a span value close the measurement range.

- In some cases the data logging software used to record the instrument data did not use the same output as the reading displayed on the sensor - many instruments have both analogue and digital outputs. In this case the user should confirm that any quality checks and calibration adjustments are relevant to the data that is recorded.

- The instrument response time provides the user with data on the appropriate time between samples. In order to ensure that one reading is independent from the previous one it is recommended to leave more than $\left(3 \mathrm{x} \mathrm{T}_{90}\right)$ between readings, at which point one reading will have less than $0.1 \%$ influence on the next. If the time between readings is too short then this can lead to significant biases in the data - as an example, a typical sampling configuration is to alternate between ambient background readings and chamber readings. If readings were taken at the $\mathrm{T}_{90}$ response time then, for typical background and chamber levels of 2 ppmv and 200 ppmv respectively, the 
chamber reading would be 180.2 ppmv and the background reading would be 21.8 ppmv. The resulting differential methane level would therefore be 158.4 ppmv rather than the correct value of 198 ppmv, leading to a $20 \%$ underestimation of methane emissions. This shows the importance of ensuring enough time between measurements to ensure independent readings.

\section{Ducting Efficiency}

Figure 4 summarises the results of injecting a known methane emission rate directly in the sample duct for an example chamber in 5 of the 6 facilities (the design at facility D prevented this type of measurement). Each column shows the ducting efficiency for an individual chamber together with the associated ( $k=2,95 \%$ confidence) uncertainty on the result, so a ducting efficiency greater than one indicates a reading above the known emission rate and a value below one indicates a reading below the known emission rate. Note that these efficiency values have been calculated having allowed for the sensor calibration results described above.

These results show a much wider spread than seen for the methane sensor calibration results and, given that methane sensor effects have been allowed for, this must be due to a combination of sampling issues/losses in the ducting and uncertainty in the chamber flow measurements.

Chamber extracted air flow measurement presents a challenging issue, both in terms of calibration and adjustment to the ambient conditions at the time of measurement. If we assume the final methane emission rate will be reported as a mass flow (i.e. grams of methane per hour), then the chamber flow measurement also needs to be determined as a mass flow. 
Therefore, if the air flow measurements are actually a volume flow measurement (i.e. $\mathrm{m} / \mathrm{s}$ ), then an air density correction will be needed to convert to a final methane mass emission rate, and this will require calibrated temperature and pressure (and potentially humidity) measurements to be made for the sample air at the point of the flow measurement. Whether this correction is needed comes down to the nature of the flow measurement method. In general terms, vane-based flow sensors measure the volume flow while hot-wire-based sensors measure the mass flow, but the details depend upon the exact nature of the sensor used. The location of the flow sensor within the duct can also influence the flow reading due to flow variation across the pipe diameter, as can obstructions and bends in the pipework. All of these issues make validation of the chamber flow reading particularly difficult, and indirect validation through full system calibration using chamber recovery tests or more extensive experiments such as described here probably provide the most viable way of assessing the accuracy of the flow measurements.

\section{Chamber Response}

Figure 5 shows a typical response curve following the injection of a controlled source of methane into the chamber, and Table 2 summarises the response results from all 6 facilities. Since the controlled emission source is effectively constant during the measurements the plateau stability reflects the flow variability within the chamber and sampling ducts, and provides a measure of the precision of a single chamber measurement point. These results show much greater variability in both plateau stability and response time, with the slower response chambers showing better plateau stability. This is not unexpected as slower response chambers will tend to smooth out any short-term variation in the flow, and there is significant variation between chamber volume and air exchange flows which drives the chamber response times. 
Another aspect of the chamber response times that should be considered is that they give information on the period a disturbance in the chamber, e.g. the chamber doors being opened, will continue to influence the readings. If the operator wishes to exclude data affected by known disturbances then results should only start to be included once a period of three times the $\mathrm{T}_{90}$ response time has passed.

Although there are large differences in the precision of a single measurement, when we consider the precision on a 24 hour average $\left(4^{\text {th }}\right.$ column of Table 2$)$ there is a much reduced spread. This value is derived from the expected $\mathrm{N}^{1 / 2}$ reduction in the measurement noise that results from averaging $\mathrm{N}$ independent measurements. The time between independent measurements is taken as the $\left(3 \times \mathrm{T}_{90}\right)$ period for each chamber, i.e. there will be more independent measurements from the faster response chambers within a given averaging time. This result shows that, for a typical 24 hour measurement period during an animal experiment, all the chambers have a measurement precision uncertainty of better than $1 \%$. Note that this precision value just shows the variability between one measurement (or average) and the next, and it does not reflect the absolute accuracy of the measurement which is discussed in the following sections.

The final column of Table 2 shows the linearity of the chamber readings to varying levels of controlled methane emissions. These values are slightly lower than those seen for the sensors themselves (see Table 1), but all show highly linear performance with $\mathrm{R}^{2}$ values of 0.99 or higher for all chambers. 


\section{Chamber Capture Efficiency}

As discussed above, the ducting efficiency was determined for an example chamber at all facilities except one (facility D), where facility configuration made the test impossible. Figure 6 shows the ratio between a reference flux release in the chamber itself against the measured value corrected using the respective facility sensor calibration function and ducting efficiency factor. Such correction removes any bias in concentration determination and / or flow measurement, isolating any differences from the reference value to the chamber itself. The result for facility $\mathrm{D}$ is the combined efficiency of the ducting and chamber.

It can be seen that there are cases of both over- and under-estimation in the chamber capture results, so it is not just a case of methane leaks out of the chamber. Given that all facilities operate chambers at pressures slightly below atmospheric, leaks into the chamber are more likely than losses out. An inward leak of ambient air into the chamber should not cause a problem, as long as the air around the chamber has the same methane concentration as the main external air inlet. However, this may not always be the case depending on farm activity (e.g. nearby ruminants emitting methane) and the presence of any other local methane sources.

Another effect which could cause the observed deviations is inhomogeneous mixing within the chamber and ducting. Some limited testing of source location dependence was carried out during the experiments. This showed that, in some chambers, the readings changed when the emission source was moved between different locations to simulate animal movements, e.g. feeding or sleeping positions (data not shown). This indicates that the intake air and emission source gases are not well mixed at the point where a sample is extracted from the chamber for measurement. The dependence of the determined emission on source location is a subject that 
this work has highlighted would be an important topic for further investigation. This effect is one of a number of cases where the presence of an animal in the chamber could potentially influence the results. It was beyond the scope of this work to address this in more detail, however the experiments described here establish the baseline chamber performance and the underpinning measurement uncertainty.

\section{Combined facility results}

Figure 7 shows the combined validation factor for every chamber tested across the six facilities, i.e. a single value combining any bias found in sensor calibration, ducting efficiency and chamber capture efficiency, together with the associated $(k=2,95 \%$ confidence level) uncertainty on each factor. As can be seen the spread in combined validation factors across all the chambers is marked, with some chambers producing measurements of less than half of that of others. An important question is whether this variability is due to chamber-to-chamber differences within facilities or facility-to-facility differences. Therefore, it is useful to determine the overall facility correction factor as is shown in Table 3. These data demonstrate that the inter-facility variance is of a similar magnitude to that between individual chambers. This result shows that the facility design and operation is the largest source of absolute uncertainty rather than chamber-to-chamber variability or instrumental noise. This result also confirms the suitability of each facility to carry out relative measurements, e.g. to compare the effectiveness of different treatments, but highlights the importance of this type of validation exercise in evaluating absolute uncertainties and establishing comparability between different facilities.

Table 4 shows a measure of overall capability for the facilities evaluated by taking the mean of the individual facility validation factors and providing the 1- $\sigma$ spread (i.e. the standard 
deviation) in these values. Table 4 also shows the mean and spread values for the three main components of a chamber facility - the sensor, the ducting and flow system, and the chamber itself. These results highlight that it is the ducting and flow system that is the main source of uncertainty in the combined chamber results.

The upper and lower panels of Table 4 shows these values with and without including data from facility B, as this was a new facility which had undergone no quality assurance testing prior to these measurements (and therefore had no prior influence in determining UK livestock emissions). The validation tests on facility B revealed a significant issue with the design which has since been rectified, and results from this facility are therefore excluded from the following general discussion.

The final element of the work was an attempt to quantify the difference the validation exercise had on the overall capability across all the facilities tested. The most appropriate measure to do this is to consider how the absolute uncertainty has changed. The absolute uncertainty is made up of both bias sources (e.g. ducting efficiency) and random sources (e.g. noise associated with methane sensor). The significant bias sources for each facility are all incorporated into the validation factor, i.e. the difference between the validation factor and unity measures the impact of off-sets in the sensor calibration, ducting efficiency and chamber capture. Random uncertainty sources such as methane sensor noise, anemometer noise, etc. are incorporated into the $24 \mathrm{~h}$ precision values shown in Table 2.

Prior to the validation exercise the bias terms were unknown, and the overall uncertainty would be dominated by these terms. The distribution of Combined Validation Factors can 
therefore be used to give an estimate of the absolute uncertainty associated with the overall capability across all facilities of $25.7 \%$ ( $k=2$, 95\% confidence).

Following the validation exercise, if each facility applies the provided validation factor to future measurements then in principle the aforementioned bias uncertainty sources are removed leaving only random sources (i.e. determined in the $24 \mathrm{~h}$ precision test) and the uncertainties associated with the determination of the validation factors. Hence, the uncertainty estimate decreases to $2.1 \%$ ( $k=2,95 \%$ confidence). It should be noted that this makes the critical assumption that all the facilities remain completely unchanged from the time the validation exercise was carried out, which is unlikely. However, whilst effects such a drift will result in an uncertainty increase from that above, it would require a very substantial facility change before values of $25.7 \%$ are approached. This notwithstanding, if a regime was put in place to repeat some of the measurements on a periodical basis this would ensure the uncertainty remains close to the $2.1 \%$ estimate. Overall, the data evidence the importance of validating national measurement infrastructure against traceable references and the potential value that can be added to future measurements as a result, particularly when looking to determine absolute emission values and when combining results from different facilities.

\section{Acknowledgements}

The authors would like to thank Elena Amico di Meane, Marta Doval Minarro and Ian Uprichard from the Gas and Particle Metrology Group at NPL for the calibration of the mass flow controllers and preparation of the reference methane standards. In addition, we would like to acknowledge the invaluable support during the field campaigns from the researchers and technical support teams at each chamber facility. 
This work was funded by Department for Environment, Food and Rural Affairs, the Scottish Government, Department of Agriculture and Rural Development (N.I.), and the Welsh Government as part of the UK's Agricultural GHG Research Platform project (www.ghgplatform.org.uk). The underpinning metrology was supported by the National Measurement System’s Chem-Bio Knowledge Base programme under the Environmental Technologies theme.

\section{References}

Armsby, H. P. 1908. The Principles of Animal Nutrition. John Wiley and Sons, New York, NY, USA.

Cammell, S. B., D. E. Beever, K. V. Skelton, and M. C. Spooner, 1981. The construction of open-circuit calorimeters for measuring the gaseous exchange and heat production in sheep and young cattle. Laboratory Practice 30:115-121.

Derno, M., H. G. Elsner, E. A. Paetow, H. Scholze, and M. Schweigel, 2009. Technical Note : A new facility for continuous respiration measurements in lactating cows. J. Dairy Sci. $92: 2804-2808$

EN 15267-3: 2007. European Standard : Air quality, Certification of automated measuring systems. Performance criteria and test procedures for automated measuring systems for monitoring emissions from stationary sources.

European Communities. 2006. The European Climate Change Programme (ECCP). Accessed Feb 11, 2014. http://ec.europa.eu/clima/policies/eccp/index_en.htm 
European Environment Agency. 2013. Trends and projections in Europe 2013 - Tracking progress towards Europe's climate and energy targets until 2020. EEA Report No 10/2013

Garnsworthy, P. C., J. Craigon, J. H. Hernandez-Medrano, and N. Saunders. 2012. On-farm methane measurements during milking correlate with total methane production by individual dairy cows. J. Dairy Sci. 95:3166-3180.

Grainger, C., T. Clarke, S. M. McGinn, M. J. Auldist, K. A. Beauchemin, M. C. Hannah, G. C. Waghorn, H. Clarke, and R. J. Eckard. 2007. Methane emissions from dairy cows measured using the sulphur hexafluoride (SF6) tracer and chamber techniques. J. Dairy Sci. 90:2755-2766.

Hellwing, A. L. F., P. Lund, M. R. Weisberg, M. Brask, and T. Hvelplund, 2012. Technical Note : Test of a low-cost and animal friendly system for measuring methane emissions from dairy cows. J. Dairy Sci. 95:6077-6085

IPCC 2006, 2006 IPCC Guidelines for National Greenhouse Gas Inventories, Prepared by the National Greenhouse Gas Inventories Programme, Eggleston H.S., Buendia L., Miwa K., Ngara T. and Tanabe K. (eds). Published: IGES, Japan.

IPCC, 2013: Climate Change 2013: The Physical Science Basis. Contribution of Working Group I to the Fifth Assessment Report of the Intergovernmental Panel on Climate Change. [Stocker, T. F., D. Qin, G.-K. Plattner, M. Tignor, S. K. Allen, J. Boschung, A. Nauels, Y. 
Xia, V. Bex and P. M. Migley (eds.)]. Cambridge University Press, United Kingdom and New York, NY, USA, 1355 pp.

Johnson, K., M. Huyler, H. Westberg, B. Lamb, and P. Zimmerman. 1994. Measurement of methane emissions from ruminant livestock using a SF6 tracer technique. Environ. Sci. Technol. 28:359-362.

Klein, L. and A. D. G. Wright, 2006. Construction and operation of open-circuit methane chambers for small ruminants. Aust. J. Exp. Agric. 46:1257-1262

McLean, J. A. and G. Tobin. 1987. Animal and Human Calorimetry. Cambridge University Press, Cambridge, UK.

McCourt, A. R., T. Yan, and S. Mayne. 2008. Validation of the sulphur hexafluoride (SF6) tracer technique as a method of predicting methane output from dairy cows. Proc. Brit. Soc. Anim. Sci. 120. Scarborough, UK.

Muñoz, C., T. Yan, D. A. Wills, S. Murray, and A. W. Gordon. 2012. Comparison of the sulfur hexafluoride tracer and respiration chamber techniques for estimating methane emissions and correction for rectum methane output from dairy cows. J Dairy Sci. 95:313948.

Murray, P. J., A. Moss, D. R. Lockyer, and S. C. Jarvis. 1999. A comparison of systems for measuring methane emissions from sheep. J. Agric. Sci. 133(Pt4):439-444. 
Pinares, C., and G. Waghorn (Eds), 2012. Technical manual on respiration chamber designs. Ministry of Agriculture and Forest, Wellington, New Zealand. Accessed Feb 11, 2014. http://globalresearchalliance.org/app/uploads/2012/03/GRA-MAN-Facility-BestPract-2012ch1.pdf and related links.

Yan, T., C. S. Mayne, F.G. Gordon, M. G. Porter, R. E. Agnew, D. C. Patterson, C. P. Ferris, and D. J. Kilpatrick. 2010. Mitigation of enteric methane emissions through improving efficiency of energy utilization and productivity in lactating dairy cows. J. Dairy Sci. 93:2630-2638. 
Tables

\begin{tabular}{|c|c|c|c|c|c|}
\hline Facility & $\begin{array}{c}\text { Test Span } \\
\text { (ppmv) }\end{array}$ & $\begin{array}{c}\text { Calibration } \\
\text { Factor }\end{array}$ & $\begin{array}{c}\text { Plateau } \\
\text { Stability }\end{array}$ & $\begin{array}{c}\mathbf{T}_{\mathbf{9 0}} \text { Response } \\
(\mathbf{s e c})\end{array}$ & $\begin{array}{c}\text { Linearity } \\
\left(\mathbf{R}^{\mathbf{2}} \mathbf{)}\right.\end{array}$ \\
\hline A & 500 & $0.987+/-0.009$ & $0.11 \%$ & 37.1 & 0.9999 \\
\hline B & 100 & $1.040+/-0.020$ & $0.93 \%$ & 33.7 & 0.9999 \\
\hline C & 50 & $0.978+/-0.083$ & $0.34 \%$ & 38.1 & 0.9999 \\
\hline D & 100 & $1.086+/-0.075$ & $0.63 \%$ & 35.4 & 0.9965 \\
\hline E & 200 & $1.008+/-0.024$ & $0.57 \%$ & 28.9 & 0.9995 \\
\hline F & 500 & $0.995+/-0.013$ & $1.01 \%$ & 25.6 & 0.9999 \\
\hline
\end{tabular}

Table 1 Summary of Sensor Calibration Results, showing for each facility sensor assessed : the span of concentrations covered, the calibration factor and its uncertainty at the span value, the variability once a stable reading is reached, the $T_{90}$ response time and the $\mathrm{R}^{2}$ linearity of response across the calibrated range. 


\begin{tabular}{|c|c|c|c|c|}
\hline Facility & $\begin{array}{c}\text { Plateau } \\
\text { Stability }\end{array}$ & $\begin{array}{c}\text { T90 } \\
\text { Response } \\
\text { (min sec) }\end{array}$ & $\begin{array}{c}\text { Precision on } \\
\mathbf{2 4} \mathbf{~ h r} \\
\text { average }\end{array}$ & $\begin{array}{c}\text { Linearity } \\
\mathbf{( R}^{2} \text { ) }\end{array}$ \\
\hline A & $1.33 \%$ & $40^{\prime} 39^{\prime \prime}$ & $0.39 \%$ & 0.9996 \\
\hline B & $1.63 \%$ & $21^{\prime} 58^{\prime \prime}$ & $0.35 \%$ & 0.9995 \\
\hline C & $11.00 \%$ & $01^{\prime} 13^{\prime \prime}$ & $0.55 \%$ & 0.9981 \\
\hline D & $4.27 \%$ & $09^{\prime} 00^{\prime \prime}$ & $0.58 \%$ & 0.9900 \\
\hline E & $2.07 \%$ & $27^{\prime} 42^{\prime \prime}$ & $0.50 \%$ & 0.9971 \\
\hline F & $2.70 \%$ & $54^{\prime} 05^{\prime \prime}$ & $0.91 \%$ & 0.9999 \\
\hline
\end{tabular}

Table 2 Summary of Chamber Response Tests, giving for an example chamber at each facility : the variability on a stable reading, the $\mathrm{T}_{90}$ response time, the measurement precision extrapolated to a $24 \mathrm{hr}$ average, and the $\mathrm{R}^{2}$ linearity of response across the tested range. 


\begin{tabular}{|c|c|c|}
\hline Facility & $\begin{array}{c}\text { Combined } \\
\text { Validation Factor }\end{array}$ & $\begin{array}{c}\text { Uncertainty } \\
\mathbf{( k = 2 )}\end{array}$ \\
\hline A & 1.045 & 0.004 \\
\hline B & 0.590 & 0.005 \\
\hline C & 1.154 & 0.030 \\
\hline D & 0.827 & 0.028 \\
\hline E & 0.945 & 0.013 \\
\hline F & 0.897 & 0.008 \\
\hline
\end{tabular}

Table 3 Combined Facility Validation Factors, giving the combined validation factor across all chambers at each facility, together with the $(k=2,95 \%$ confidence) uncertainty on the derivation of each factor. 


\begin{tabular}{|l|c|c|}
\hline $\begin{array}{l}\text { Combined } \\
\text { Validation Factor }\end{array}$ & Mean & 1- $\boldsymbol{\sigma}$ Spread \\
\hline Complete facility & 0.9097 & $19.4 \%$ \\
\hline Methane Sensor & 1.001 & $2.4 \%$ \\
\hline Ducting incl. flow & 0.9308 & $19.8 \%$ \\
\hline Chamber only & 0.9849 & $4.0 \%$ \\
\hline
\end{tabular}

\begin{tabular}{|l|c|c|}
\hline $\begin{array}{l}\text { Combined } \\
\text { Validation Factor }\end{array}$ & Mean & 1- $\boldsymbol{\sigma}$ Spread \\
\hline Complete facility & 0.9736 & $12.8 \%$ \\
\hline Methane Sensor & 0.992 & $1.3 \%$ \\
\hline Ducting incl. flow & 0.9968 & $15.3 \%$ \\
\hline Chamber only & 0.9971 & $3.4 \%$ \\
\hline
\end{tabular}

Table 4 Chamber Performance Summary, showing the mean validation factor across the facilities and the 1- $\sigma$ spread of values. The results are given for the combined facilities, and separately for the three main system elements in each facility (sensor, ducting and flow, chamber). The upper table includes all chamber facilities, the lower table excludes the new, untested facility (facility B). 


\section{Figures}

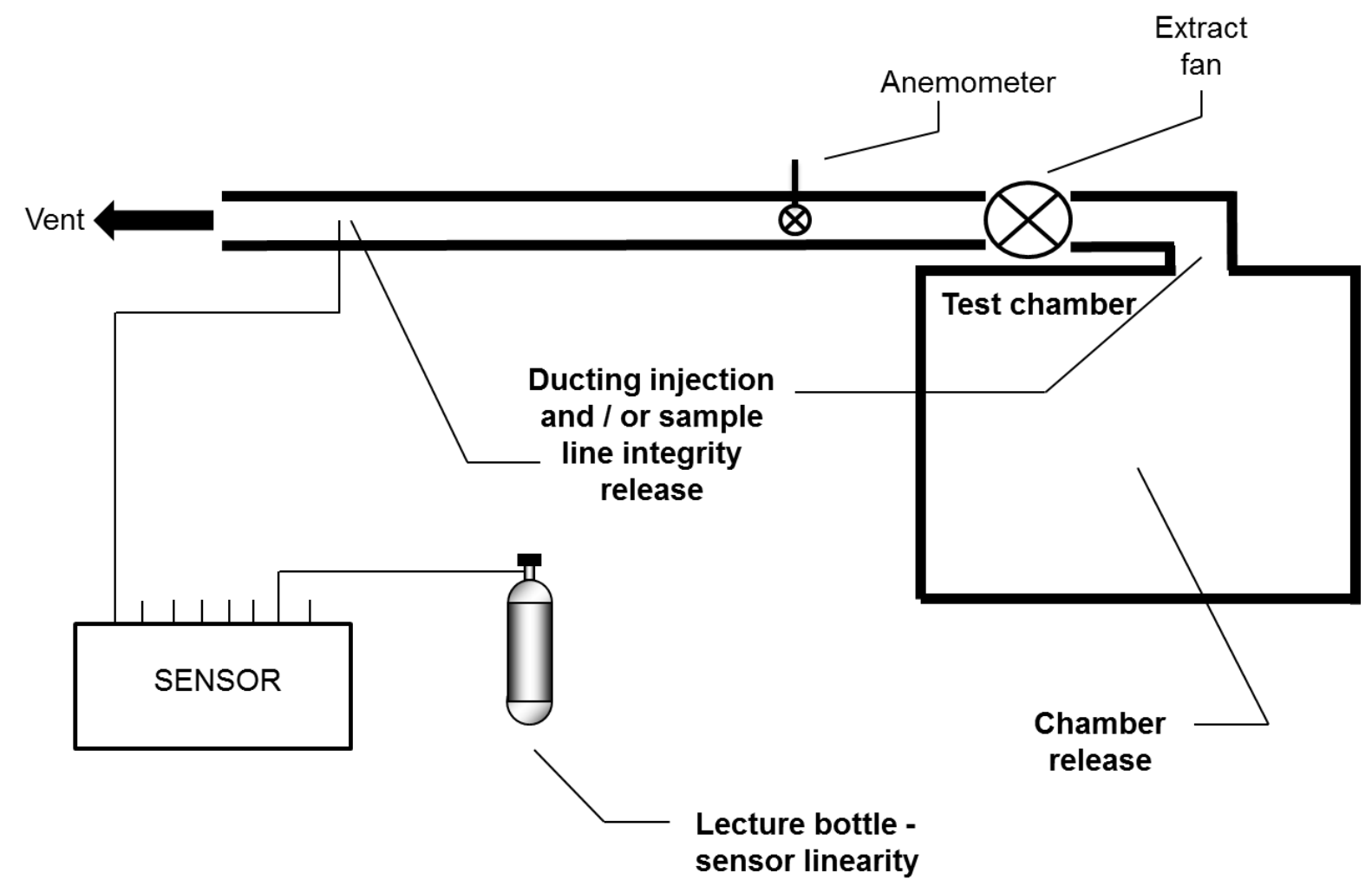

Figure 1 Schematic of operational principle of livestock respiration chambers across five UK research farms. Mass flow controllers, sampling line and diffuser only included during National Physical Laboratory testing of facilities. 
T.D. Gardiner et al.

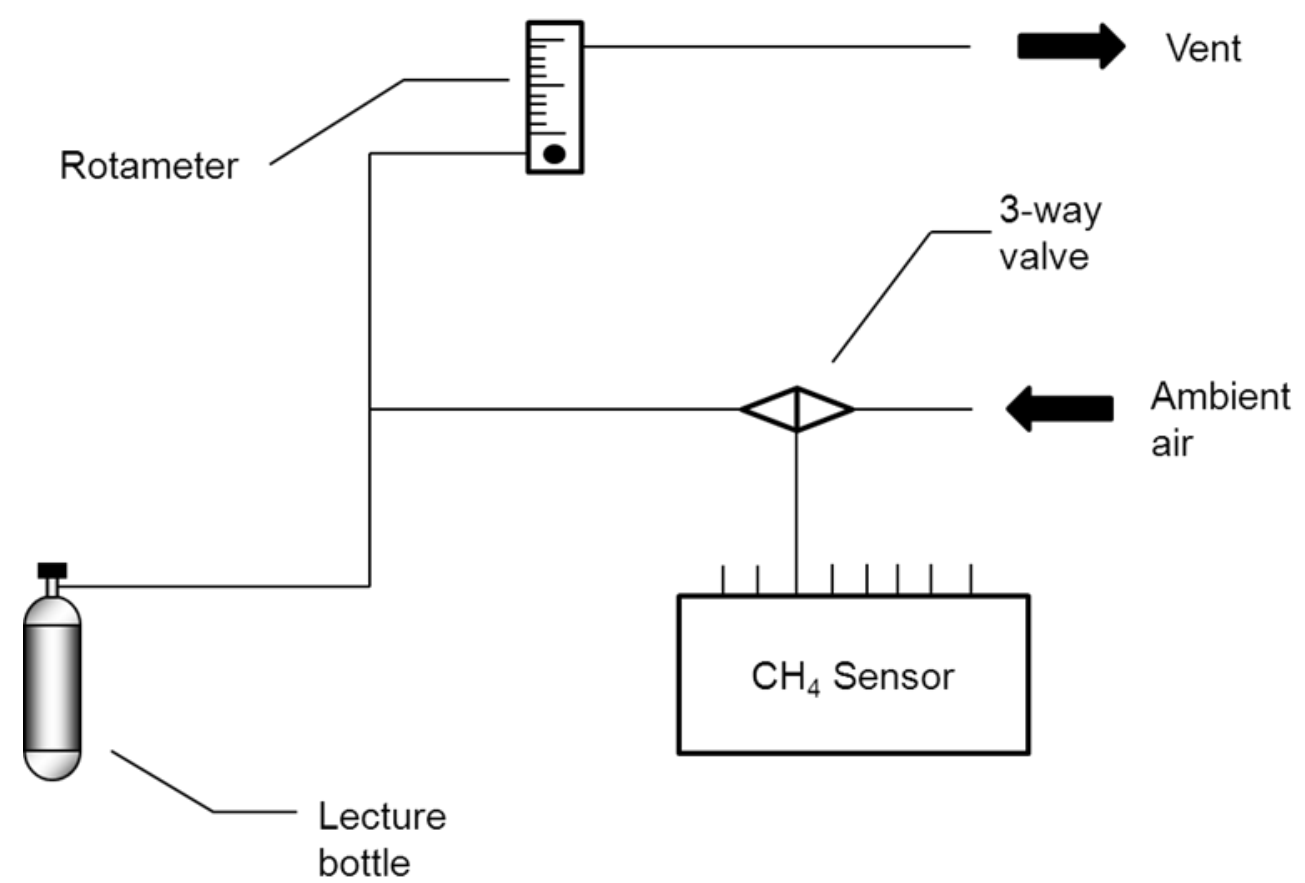

Figure 2 Schematic of gas delivery system used to evaluate the response of the methane sensors. The 3-way value allows switching between ambient and calibration gas, and the rotameter is used to ensure a positive by-pass flow to the vent. 


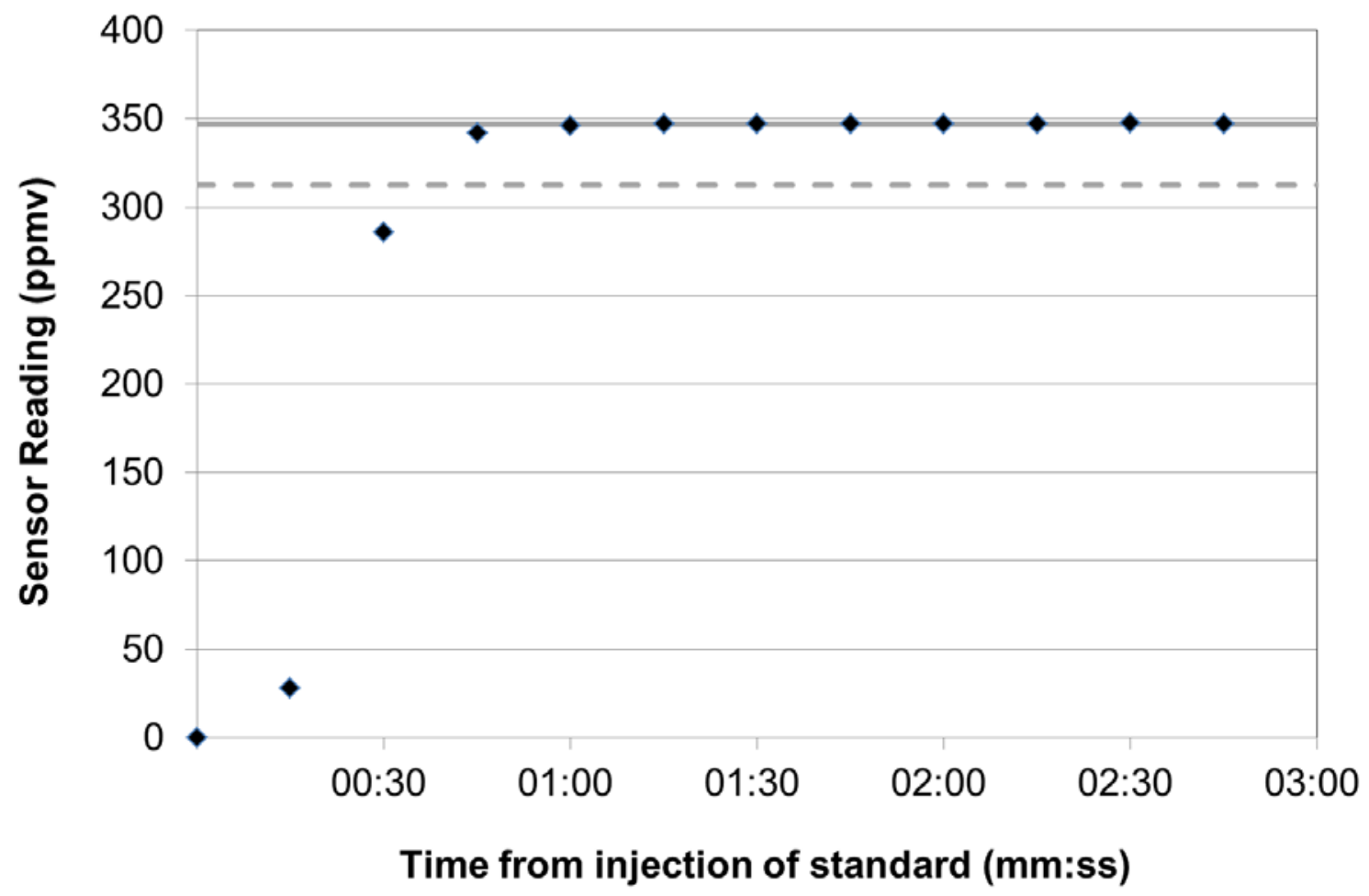

Figure 3 Response of a methane sensor to injection of calibration standard of methane. Black diamonds show the sensor's response with time measured every $10 \mathrm{~s}$, the solid line shows the plateau reading level, and the dotted line shows the $90 \%$ value of plateau reading. 


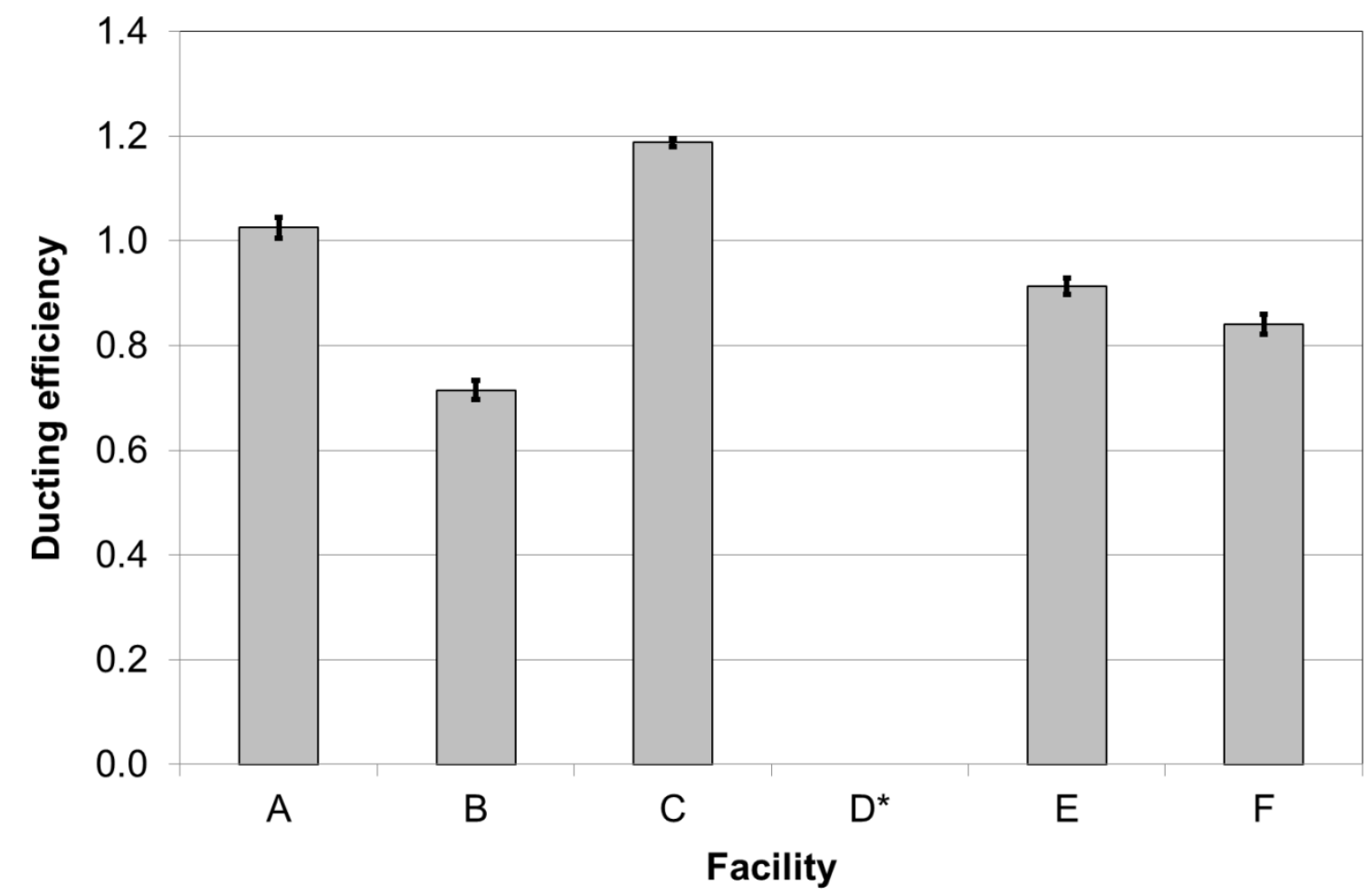

Figure 4 Ducting efficiency results. Columns give the efficiency values for the individual systems tested together with the ( $k=2,95 \%$ confidence) uncertainties on the determination of the efficiencies.

*Note that, due to facility design, it was not possible to determine the ducting efficiency result for facility D. 


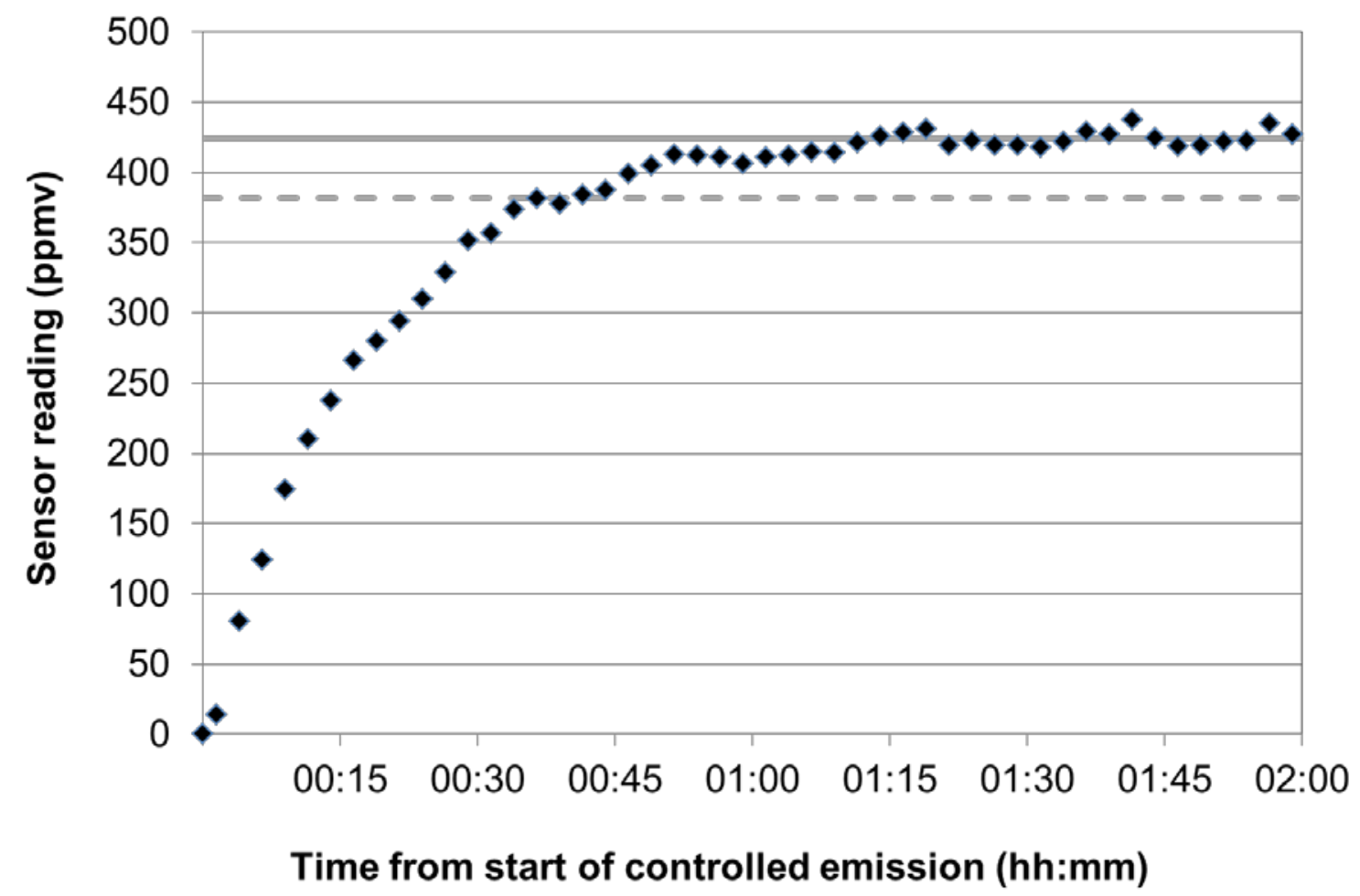

Figure 5 Response of system to injection of controlled flow of methane into chamber. Black diamonds show the measured response with time, the solid line shows the plateau reading level, and the dotted line shows the $90 \%$ value of plateau reading. 


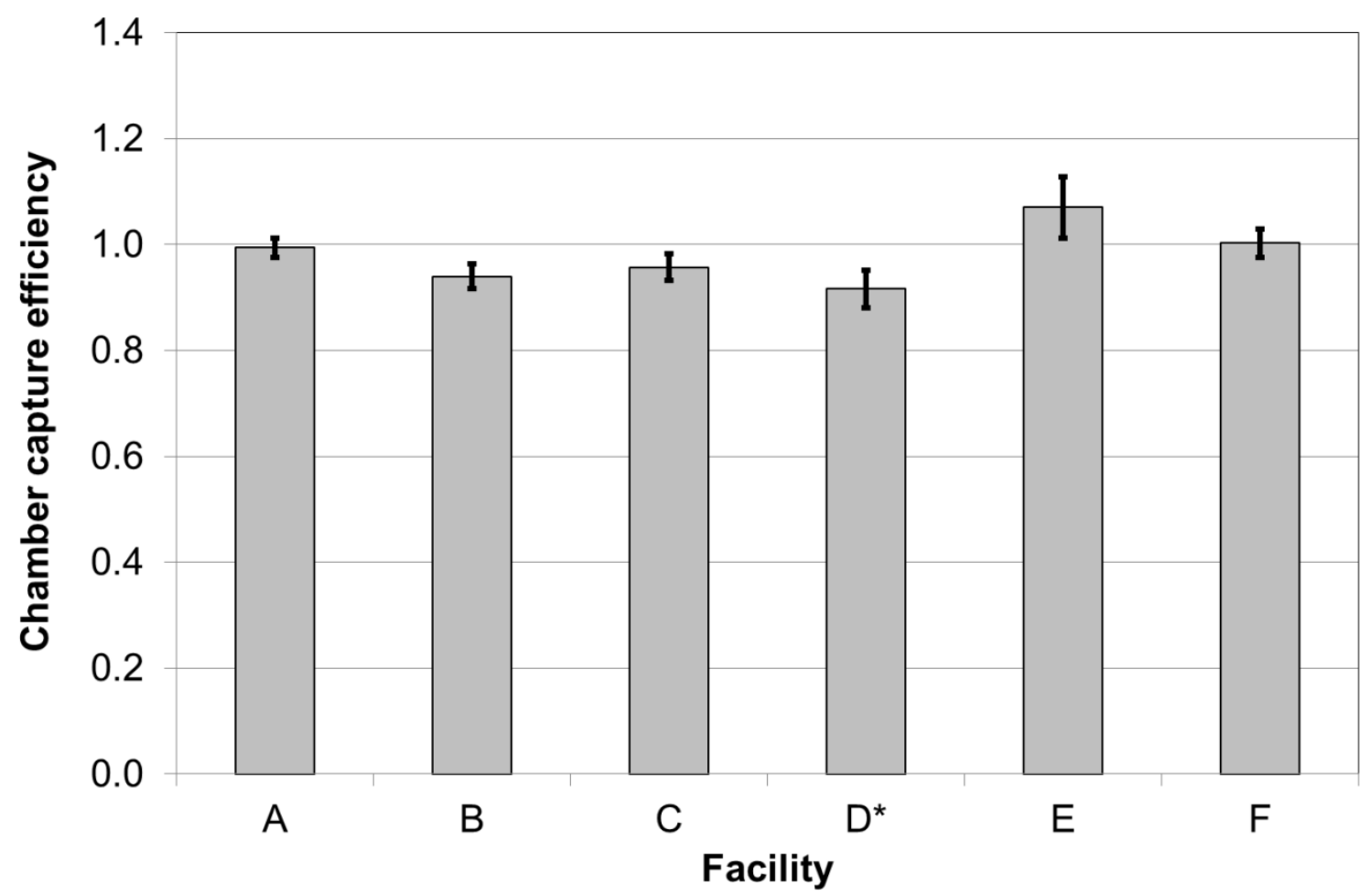

Figure 6 Chamber Capture Efficiencies. Columns give the efficiency values for the individual chambers tested together with the ( $k=2,95 \%$ confidence) uncertainties on the determination of the efficiencies.

*Note that for facility D the efficiency shown is the combined efficiency of the chamber capture and the ducting. 


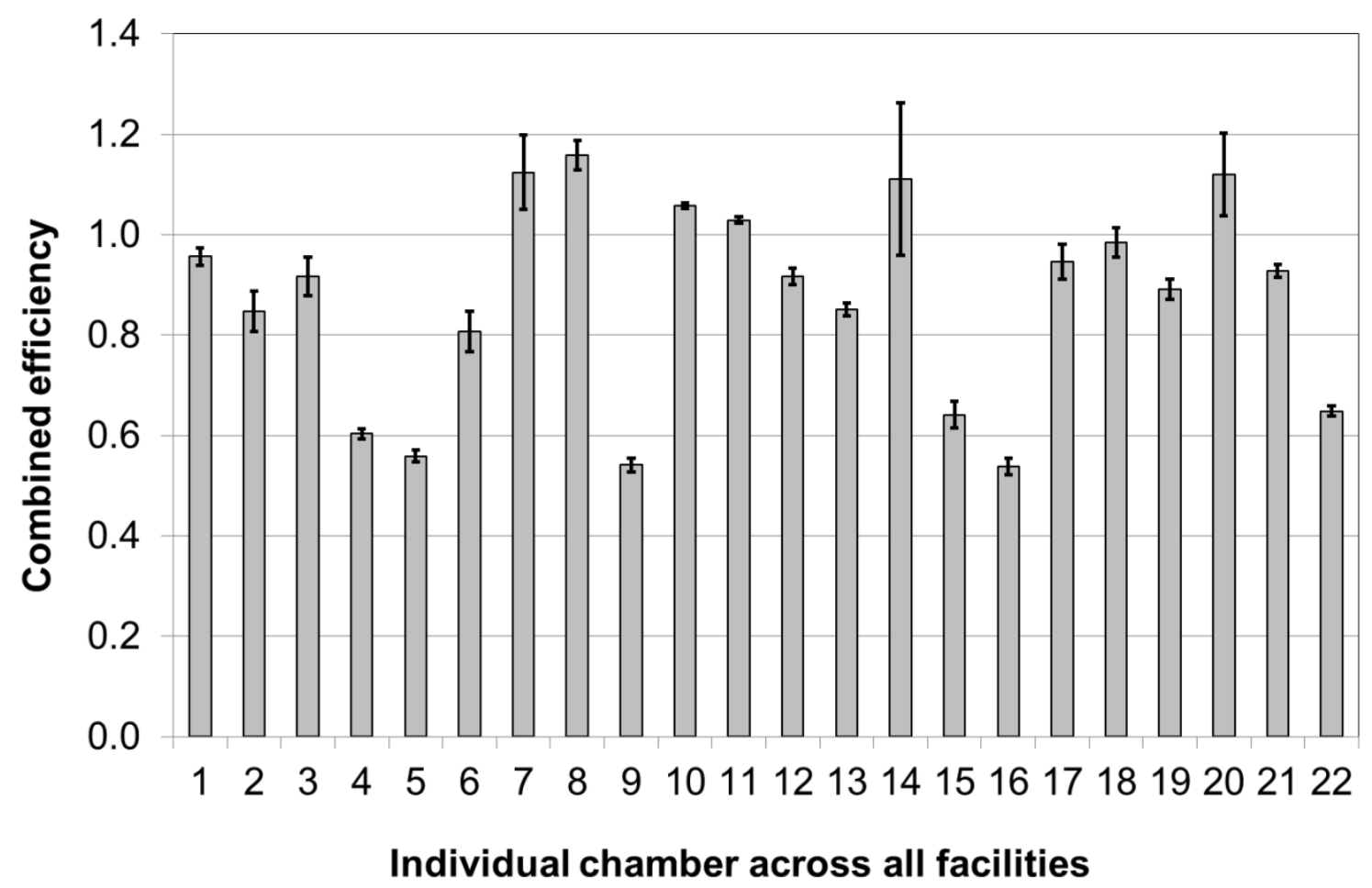

Figure 7 Individual Compete Chamber Efficiencies. Columns give the efficiency values for the individual systems tested together with the ( $k=2$, 95\% confidence) uncertainties on the determination of the efficiencies. 